\title{
OSTEONECROSE DE MANDÍBULA ASSOCIADA AO USO DE BISFOSFONATOS - RELATO DE CASO CLÍNICO
}

Giselle Pereira CAMARGO, Ana Paula Santos de SOUZA, José Miguel AMENÁBAR, Cleto Mariosvaldo PIAZZETA, Cassius Carvalho TORRES-PEREIRA

Paciente do sexo masculino, 77 anos, leucoderma, procurou a disciplina de Estomatologia da UFPR queixando-se de dor e ausência de cicatrização após uma exodontia. $\mathrm{Na}$ anamnese relatou ter sido tratado para um câncer de próstata e medicado com protocolo para prevenção de metástases ósseas à base de Pamidronato. Ao exame clínico intrabucal constatou-se a presença de exposição óssea e supuração na região anterior da mandíbula com tempo de evolução de quatro meses. As imagens radiográficas evidenciavam áreas de irregularidades ósseas, indicativas de osteonecrose. O paciente foi submetido à cirurgia para remoção do tecido necrótico e irrigação com antimicrobiano tópico. Os fragmentos foram enviados para exame anatomopatológico cujo resultado confirmou a hipótese clínica de osteonecrose. O presente relato de caso discutirá as dificuldades diagnósticas e terapêuticas que envolvem a abordagem de pacientes medicados com bifosfonatos e a recente descrição de osteonecrose, particularmente dos maxilares, como efeito colateral do uso destes fármacos. 